\title{
Pedagogia de projetos: proposição de sua utilização no ensino de graduação e pós- graduação em enfermagem
}

\author{
Max Lopes Wada*, Mildren Lopes Wada Duque**, Zaida Aurora Sperli Geraldes Soler, D.Sc. ***
}

Em várias partes do mundo, em especial em países da Europa e algumas instituições de ensino dos Estados Unidos, a proposta educativa denominada pedagogia de projetos ou metodologia de projeto, sistematizada pelas inteligências múltiplas, é praticada em instituiçóes de ensino democráticas e de excelência na formação, além de divulgada no meio científico em eventos, artigos, livros, dissertaçóes e teses. Fernando Hernandez, grande pesquisador espanhol sobre o trabalho com projetos, é um dos estudiosos que deu o nome de "pedagogia de projetos", destacando essa nova postura pedagógica, uma inovadora maneira de compreender e vivenciar o processo educativo, rompendo com a visão tradicional da educação e atendendo a alguns desafios da sociedade atual. Não significa uma mera técnica, mas uma maneira de desenvolver a formação escolar baseada no ensino para compreensão, como uma atividade cognoscitiva, experiencial, relacional, investigativa e dialógica [1].

Por meio desta pedagogia são desenvolvidas além de conteúdos, as competências para aplicá-los na prática. Estas competências são desenvolvidas pelo estímulo das inteligências múltiplas dentro de cada projeto.

Considerando as facilidades que a sociedade dispóe de comunicação e trânsito de informaçóes pela internet, é de se esperar que a aprendizagem escolar fosse mais dinâmica e integrada com a vida atual. A pedagogia de projetos atende aos preceitos dos Parâmetros Curriculares Nacionais, da Lei de Diretrizes e Bases da Educação Nacional, envolvendo o ensino com muitos conteúdos e organizando-se em torno de uma produção determinada. Favorece a aprendizagem

* Graduado em Direito e Teologia, Mestrando em Enfermagem pela FAMERP na área de Educação e Saúde, co-fundador e gestor da Escola Maria Peregrina, professor de capacitação teológica no Instituto de Educação e Ciência Maria Peregrina, professor de Ética e Contexto Legal na pós-graduação Lato Sensu em Medicina do Trabalho, Enfermagem do Trabalho e Enfermagem Obstétrica, membro do Grupo de pesquisa "Núcleo de Estudos sobre Morbidade Referida e Gestão do Trabalho em Saúde» - NEMOREGES

${ }^{*}$ Graduada em Letras e Psicologia, Mestranda em Enfermagem pela FAMERP na área de Educação e Saúde, pós-graduada em psicopedagogia e gestão educacional, fundadora e coordenadora pedagógica da Escola Maria Peregrina, formadora dos docentes na rede SENAC, palestrante em congressos educacionais, professora de Capacitação em Pedagogia de Projetos do Instituto de Educação e Ciência Maria Peregrina, membro do Grupo de pesquisa "EDUS".

***Obstetriz, Enfermeira, Enfermeira do Trabalho, Licenciatura em Enfermagem, Livre-Docente em Enfermagem da FAMERP na área Enfermagem Obstétrica, organizadora e Presidente do Centro de Estudos do Departamento de Enfermagem em Saúde Coletiva e Orientação Profissional-CEDESCOP - FAMERP, organizadora e coordenadora dos Cursos de Especialização em Enfermagem Obstétrica, ministrado na FAMERP desde 2000, vinculado ao CEDESCOP; Diretora Adjunta de Extensão de Serviços à Comunidade da FAMERP de 2001 a 2012. Docente e orientadora da graduação e pós-graduação Lato Sensu e Stricto Sensu da FAMERP; coordenadora do Programa de Enfermagem - Mestrado Acadêmico proposto na CAPES em 2011 
significativa, pois a estrutura de funcionamento dos projetos cria motivação nos alunos para o aprendizado com autonomia [2].

$\mathrm{Na}$ pedagogia de projetos, o aluno tem participação ativa no seu processo de aprendizagem, com protagonismo e constante construçáo da autonomia e solidariedade. Ele se torna o "pesquisador-mor", com a liberdade de pesquisar segundo seus interesses e seu projeto de aprendizado é a grande proposta pedagógica. É o aluno que propóe os temas transversais. Como valoriza o interesse do aluno, esse processo pedagógico gera situaçóes de aprendizagem reais e diversificadas, incentivando as habilidades e atitudes essenciais para o desenvolvimento e a manutenção da resiliência $[3,4]$.

Os autores Max Lopes Wada e Mildren Lopes Wada Duque são os idealizadores da utilizaçáo da pedagogia de projetos em uma Escola de Ensino Fundamental, na cidade de São José do Rio Preto, denominada "Maria Peregrina" [5]. Trata-se de uma escola particular, porém gratuita, que há 9 anos trabalha com a pedagogia de projetos, ressaltando o ensino com foco na formação humana, na valorização do indivíduo, na participação construtiva e no estímulo a uma educação que envolva toda a comunidade.

$\mathrm{Na}$ Escola Maria Peregrina todo processo de ensino-aprendizagem parte de situaçóes-problemas trazidas pelos próprios alunos ou por situaçóes significativas relacionadas ao meio em que convivem (o que querem pesquisar? por que querem pesquisar o assunto? o que já sabem sobre ele?). A partir da problematização é traçado o desenvolvimento e/ou o Itinerário Proposto do Projeto. Além disso, a participação efetiva da família é o grande alicerce do método adotado, juntamente com o acompanhamento individualizado de cada estudante.

$O$ interesse na utilização da pedagogia de projetos no ensino de Enfermagem, pela Profa. Dra. Zaida Aurora Sperli Geraldes Soler emergiu da oportunidade de orientar em nível de mestrado, junto ao Programa de Enfermagem de Mestrado Acadêmico, o teólogo e educador Max Lopes Wada, que está desenvolvendo pesquisa denominada "Qualidade de Vida de Estudantes do Ensino Fundamental de Escola que utiliza a Pedagogia de Projetos", vinculada ao Núcleo de Estudos sobre Morbidade Referida e Gestão do Processo de Trabalho em Saúde (NEMOREGES).

Estamos iniciando a utilização da Pedagogia de Projetos em duas disciplinas da $1^{a}$ série de um curso de graduação em Enfermagem - uma de metodologia científica e outra que envolve conteúdos de história, ética e legislação em Enfermagem, assim como junto a um curso de pós-graduação Lato Sensu - Especialização em Enfermagem Obstétrica. A Profa. Dra. Zaida é responsável pelas disciplinas citadas da graduação em Enfermagem e organizadora e coordenadora geral dos cursos de Especialização em Enfermagem Obstétrica.

Esperamos que a utilização da pedagogia de projetos no ensino de enfermagem se desenvolva em um ambiente fértil de aprendizagem. Vamos buscar que o processo de ensino-aprendizagem seja construído com muita precisáo, para atender ao grande objetivo de desenvolvimento das capacidades dos alunos de graduação e pós-graduação em Enfermagem participantes deste projeto, em ordem cognitiva, física, afetiva, de relação interpessoal e inserção social, ética e estética, tendo em vista uma formação ampla e humanística. Tem tudo para "dar certo."

\section{Referências}

1. Girotto CGGS. A (re) significação do ensinar-e-aprender: a pedagogia de projetos em contexto. Núcleos de Ensino da Unesp 2005;1(1):89.

2. Demarzo MMP, Aquilante AG. Saúde Escolar e Escolas Promotoras de Saúde. In: Programa de Atualização em Medicina de Família e Comunidade. Porto Alegre: Artmed: Pan-Americana; 2008.

3. Hernandes F, Ventira M. A organização do currículo por projetos de trabalho. $5^{\mathrm{a}}$ ed. Porto Alegre: Artmed; 1998.

4. Sabba CG. A busca pela aprendizagem além dos limites escolares [tese]. Sáo Paulo: Universidade de São Paulo; 2009.

5. Duque MLW, organizador. Sistema de Ensino Maria Peregrina. São José do Rio Preto: Escola Maria Peregrina; 2010. 